\title{
Syringaldazine Peroxidase Stimulates Lignification by Enhancing Polyamine Catabolism in Wheat during Heat and Drought Stress
}

\author{
S. BALA ${ }^{1}$, B. AsthIR ${ }^{1 *}$ and N.S. BAINS ${ }^{2}$ \\ ${ }^{1}$ Department of Biochemistry, Punjab Agricultural University, Ludhiana-141004, Punjab, India \\ ${ }^{2}$ Department of Plant Breeding and Genetics, Punjab Agricultural University, Ludhiana-141004, Punjab, India
}

(Received 8 December 2015; Accepted 21 March 2016;

Communicated by A. Pécsváradi)

\begin{abstract}
Six wheat cultivars, namely PBW 343, PBW 550 (stress susceptible), PBW 621, PBW 175 (drought tolerant), C 306 and HD 2967 (heat tolerant), were used in this study to evaluate the effect of heat and drought stress on the activities of peroxidases (POXs), diamine oxidase (DAO), polyamine oxidase (PAO) and arginine decarboxylase (ADC) and ornithine decarboxylase (ODC) in relation to contents of polyamines (PAs), lipid peroxide and lignin. High temperature (HT) elevated activities of syringaldazine peroxidase (SPX), guaiacol peroxidase (GPX) and coniferyl alcohol peroxidase (CPX) in heat tolerant cultivars while, drought stress accentuated ADC/ODC activities in drought tolerant cultivars. Both heat and drought stress enhanced activities of DAO and PAO alongwith contents of $\mathrm{H}_{2} \mathrm{O}_{2}$ in PBW 175 and C 306. Amongst studied POXs, SPX activity was relatively more and coincided well with lignin content under HT stress while, the levels of ADC/ODC paralleled with putrescine and spermidine contents under drought stress. Higher build up of thiobarbituric acid reactive substances in cultivars PBW 343 and PBW 550 indicated their membrane instability during both the stresses. Our results revealed that SPX mediated lignification leading to higher cell wall rigidity under heat stress and drought increased PAs involved in ROS scavenging due to presence of positive charges which can bind strongly to the negative charges in cellular components such as proteins and phospholipids and thereby stabilize the membranes under stress conditions.
\end{abstract}

Keywords: arginine decarboxylase, lignin, membrane stability, ornithine decarboxylase, peroxidases

\section{Introduction}

Heat and drought are two main environmental stresses frequently encountered by wheat. High temperature is often accompanied by drought stress under field condition and may impair all the vital processes such as photosynthesis, membrane integrity, functioning of enzymes, proteins and hormones (Kumar et al. 2011). These stresses enhanced production of reactive oxygen species (ROS) and hydrogen peroxide $\left(\mathrm{H}_{2} \mathrm{O}_{2}\right)$, which causes damage to membrane lipids and proteins (Suzuki and Mittler 2006). To mitigate adverse

*Corresponding author; E-mail: b.asthir@rediffmail.com 
effect of these stresses, plants adopt different defence strategies like detoxification of ROS, changes in cell wall structure and alteration in polyamine metabolism.

Heat and drought stress often leads to enhanced production of superoxide radical, hydroxyl radical and hydrogen peroxide $\left(\mathrm{H}_{2} \mathrm{O}_{2}\right)$. Hydrogen peroxide production is mediated by diamine oxidase (DAO) and polyamine oxidase (PAO) activities and its further utilization by peroxidases (POX) is well documented (Goyal and Asthir 2010). The dual effect of these stresses dramatically changes the activity of POX and thereby lignin deposition. Reports in the literature indicate different types of POXs present in the cell wall; however their precise function in relation to lignification is still obscure.

Peroxidase is one of the main enzymes responsible in combating oxidative stress generated by ROS. Excessive production of ROS under stress conditions is responsible for causing high damage to plant cell structure (Kotak et al. 2007). The composition of cell wall gets immensely disrupted under stress conditions due to lipid peroxidation of the unsaturated fatty acid present in the cell wall (Tao et al. 2009). Although, cell-wall-associated POXs uses $\mathrm{H}_{2} \mathrm{O}_{2}$ for cell wall lignification that could reinforce the cell wall to maintain functional integrity (Denness et al. 2011), but source of its production is still a matter of concern in wheat leaves.

Polyamines not only protect plants against abiotic stresses but also have anti-stress effects due to their antioxidant properties and cell wall stabilizing abilities (Liu et al. 2010). Diamine oxidase and PAO are thought to play a major role in catabolism of PAs and $\mathrm{H}_{2} \mathrm{O}_{2}$ production, which may contribute to defence responses in plants under different stresses (Iannone et al. 2013). DAO catalyzes oxidative deamination of diamines (Put and cadaverine) to produce D-pyrroline with the release of ammonia and $\mathrm{H}_{2} \mathrm{O}_{2}$. Oxidation of PAs (Spd and Spm) by PAO yields 1,3-aminopropylpyrroline alongwith $\mathrm{H}_{2} \mathrm{O}_{2}$ and diaminopropane production.

Wheat cultivars used in this study were characterized earlier in our laboratory for heat stress tolerance in terms of carbon utilization efficiency and yield potential. Some of them were also screened for antioxidant scavenging capacity under heat stress (Goyal and Asthir 2010). Moreover, the present study highlights the impact of heat and drought stress imposed separately to have comparative analysis of their impact in relation to PAs metabolism and metabolic pathways getting affected in different genotypes.

\section{Materials and Methods}

\section{Plant material and treatment}

Wheat (Triticum aestivum L.) cultivars characterized earlier biochemically and physiologically as stress susceptible (PBW 343 and PBW 550), drought tolerant (PBW 621 and PBW 175) and heat tolerant (C 306 and HD 2967) were grown in pots ( $23 \mathrm{~cm}$ high, $22 \mathrm{~cm}$ in top diameter and $15 \mathrm{~cm}$ in bottom diameter) and filled with $10 \mathrm{~kg}$ soil. The soil was sandy loam with $\mathrm{pH} 7.3$ to 7.4 . The pots were placed in field and sheltered from rain by a removable, transparent polythene shelter. Five seeds were sown in each pot. There were 10 pots for each cultivar in three replications. Plants were watered three times a week so 
as to maintain soil water content close to field capacity. Drought was maintained in $1 / 3$ of the pots by withholding irrigation at 40 days after sowing (DAS), i.e. twenty days before sampling. Heat shock was applied by transferring $1 / 3$ of the pots in growth chamber maintained at maximum temperature of $36{ }^{\circ} \mathrm{C}$ with $16 \mathrm{~h}$ light and minimum of $24{ }^{\circ} \mathrm{C}$ with $8 \mathrm{~h}$ dark photoperiod for three days with three days recovery period (exposure to normal temperature conditions) before sampling.

\section{Peroxidase and polyamine metabolising enzymes extraction and assay}

Fresh leaf samples $(0.5 \mathrm{~g})$ were homogenized in $50 \mathrm{mM}$ Na-phosphate buffer $(\mathrm{pH} 7.0)$ containing $0.1 \mathrm{mM}$ EDTA and 1\% polyvinyl pyrrolidone (PVPP). The homogenate was filtered through four layers of cheesecloth and then centrifuged at $4{ }^{\circ} \mathrm{C}$ for $20 \mathrm{~min}$ at $15,000 \mathrm{~g}$. All operations of enzyme extraction were performed at $0-4{ }^{\circ} \mathrm{C}$ and the enzyme assays were carried out at room temperature $\left(25 \pm 1^{\circ} \mathrm{C}\right)$. Guaiacol peroxidase (GPX) activity was determined according to Lee and Lin (1995). Syringaldazine peroxidase (SPX) activity was determined as described by Quiroga et al. (2000). Coniferyl alcohol peroxidase (CPX) was measured by Savidge and Udagama-Randeniya (1992).

The leaf samples were extracted in $100 \mathrm{mM}$ potassium-phosphate buffer ( $\mathrm{pH} 6.5$ ) containing $5 \mathrm{mM}$ dithiothreitol and the extract was centrifuged at $16,000 \mathrm{~g}$ for $20 \mathrm{~min}$ at $4{ }^{\circ} \mathrm{C}$. The supernatant was used as source of enzyme. DAO and PAO activities were assayed as per Asthir et al. (2002). Activities are expressed as nmol (D-pyrroline) $\mathrm{g}^{-1} \mathrm{FW} \mathrm{h}^{-1}$ for $\mathrm{DAO}$ and PAO.

The ADC and ODC activities were assayed as described by Birecka et al. (1985) with some modifications (Zao and Liu 2000). The ADC and ODC activities were expressed as

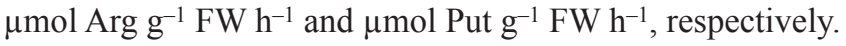

\section{Estimation of contents of thiobarbituric acid reactive substances, hydrogen peroxide and lignin}

The concentration of lipid peroxide products was determined in leaves tissues in terms of thiobarbituric acid reactive substances (TBARs) content (Heath and Packer 1968).

Determination of $\mathrm{H}_{2} \mathrm{O}_{2}$ content was performed according to the method of Sergiev et al. (1997).

Lignin was determined according to Lin and $\mathrm{Kao}$ (2001) against $\mathrm{NaOH}$ blank at 280 $\mathrm{nm}$. The amount of lignin was calculated from a linear calibration curve $(0-40 \mu \mathrm{g})$ built with commercial alkali lignin.

\section{Analysis of polyamines}

The PAs concentrations were measured according to the methods of Dhillon-Grewal et al. (1992). Extraction was done at room temperature for $30 \mathrm{~min}$ and absorbance was measured at $505 \mathrm{~nm}$. A comparative curve was plotted with the help of standard polyamines passed previously through the Dowex-50 column. 


\section{Histochemical staining of lignin}

Detection of lignin was performed by phloroglucinol/HCl staining (Nakashima et al. 2008). Wheat leaves were macerated and immersed in 2\% phloroglucinol for $10 \mathrm{~min}$ followed by immersion in concentrated $\mathrm{HCl}$ for $2 \mathrm{~min}$, and finally washed in $75 \%$ glycerol for $5 \mathrm{~min}$. Sections were then photographed under an Olympus motorized system microscope (CX41, Olympus Co., Tokyo, Japan) at 400 magnifications.

\section{Statistical analysis}

All data are presented as the mean value of three independent sets of experiments. Each value is presented as mean \pm standard error (SE). Statistical analysis was carried out by one-way analysis of variance (ANOVA) and the mean differences were compared by Tukey test using SPSS Windows version 17.0 (SPSS). Different letters indicate that the means were significantly different at $p<0.05$.

\section{Results}

\section{Effect of heat and drought stress on activities of peroxidases}

High temperature (HT) and drought stress significantly elevated activities of cell wall peroxidases, viz. guaiacol peroxidase (GPX), coniferyl alcohol peroxidase (CPX) and syringaldazine peroxidase (SPX) in six genotypes (PBW 343, PBW 621, PBW 550, PBW 175, C 306 and HD 2967) of wheat (Table 1). Maximum activity of GPX was observed in HD 2967 under HT and in PBW 621 under drought stress. High temperature induced manyfold increase in GPX activity in comparison to control and similar trend was observed for CPX activity. However, SPX activity was maximum in HD 2967 under drought and in C 306 under HT stress whereas, under control conditions it was maximum in PBW 550 but further increase was non-significant under stress conditions. Amongst all peroxidases, SPX was the predominant enzyme over other peroxidases as shown in Table 1.

\section{Effect of heat and drought stress on polyamine metabolizing enzymes and contents}

Polyamine catabolising enzymes, viz. diamine oxidase (DAO) and polyamine oxidase (PAO) are involved in putrescine (Put) and spermidine ( $\mathrm{Spd}$ ) catabolism which gets significantly enhanced under heat and drought stresses. Whereas, polyamine synthesising enzymes, viz. arginine decarboxylase (ADC) and ornithine decarboxylase (ODC) decreased under both the stresses (Table 1). Maximum activities of DAO and PAO were found in PBW 175 followed by C 306 and HD 2967 under drought and HT. Interestingly, under control condition higher activity of PAO was found in PBW 343, PBW 175 and PBW 621. Maximum DAO activity was observed in HD 2967 under HT and in PBW 175 under drought stress condition. Genotype C 306 exhibited manyfold increase compared to control in DAO activity. Polyamine oxidase activity was highest in PBW 621 under drought and in C 306 under heat stress. 
Table 1. Effect of drought and heat stress on GPX, SPX, CPX, DAO, PAO, ADC and ODC activities in leaves of six wheat genotypes

\begin{tabular}{|c|c|c|c|c|c|c|}
\hline \multicolumn{7}{|c|}{$\mathrm{GPX}(\mathrm{mmol} / \mathrm{min} / \mathrm{g} \mathrm{FW})$} \\
\hline Treatment & PBW 343 & PBW 550 & PBW 175 & PBW 621 & C 306 & HD 2967 \\
\hline Control & $0.103^{\mathrm{c}}$ & $0.135^{\mathrm{a}}$ & $0.226^{\mathrm{ab}}$ & $0.316^{\mathrm{b}}$ & $0.203^{\mathrm{ab}}$ & $0.203^{\mathrm{ab}}$ \\
\hline Drought & $0.17^{b}$ & $0.137^{\mathrm{b}}$ & $0.256^{\mathrm{b}}$ & $0.398^{\mathrm{a}}$ & $0.278^{a}$ & $0.33^{\mathrm{d}}$ \\
\hline Heat stress & $0.374^{\mathrm{a}}$ & $0.398^{\mathrm{a}}$ & $0.55^{\mathrm{a}}$ & $0.65^{\mathrm{c}}$ & $0.70^{\mathrm{e}}$ & $0.62^{\mathrm{d}}$ \\
\hline \multicolumn{7}{|c|}{$\mathrm{SPX}(\mathrm{mmol} / \mathrm{min} / \mathrm{g} \mathrm{FW})$} \\
\hline Control & $8.41^{\mathrm{a}}$ & $10.82^{\mathrm{a}}$ & $8.73^{a}$ & $9.91^{b}$ & $6.54^{c}$ & $7.54^{\mathrm{a}}$ \\
\hline Drought & $9.27^{\mathrm{a}}$ & $7.82^{\mathrm{ab}}$ & $8.91^{a}$ & $12.41^{b}$ & $8.18^{d}$ & $12.45^{\mathrm{a}}$ \\
\hline Heat stress & $10.00^{\mathrm{a}}$ & $12.09^{\mathrm{b}}$ & $10.09^{\mathrm{a}}$ & $8.91^{\mathrm{c}}$ & $13.64^{\mathrm{d}}$ & $12.73^{\mathrm{bc}}$ \\
\hline \multicolumn{7}{|c|}{$\mathrm{CPX}(\mathrm{mmol} / \mathrm{min} / \mathrm{g} \mathrm{FW})$} \\
\hline Control & $1.06^{\mathrm{ab}}$ & $1.60^{\mathrm{cd}}$ & $1.30^{\mathrm{a}}$ & $1.80^{\mathrm{d}}$ & $2.55^{\mathrm{b}}$ & $2.98^{\mathrm{bc}}$ \\
\hline Drought & $1.16^{\mathrm{c}}$ & $2.00^{\mathrm{b}}$ & $2.61^{\mathrm{ab}}$ & $3.26^{\mathrm{a}}$ & $2.56^{\mathrm{a}}$ & $4.33^{\mathrm{d}}$ \\
\hline Heat stress & $2.11^{b}$ & $2.50^{\mathrm{a}}$ & $3.00^{\mathrm{a}}$ & $2.78^{c}$ & $3.38^{\mathrm{d}}$ & $4.51^{\mathrm{e}}$ \\
\hline \multicolumn{7}{|c|}{$\mathrm{DAO}(\mu \mathrm{mol} / \mathrm{min} / \mathrm{g} \mathrm{FW})$} \\
\hline Control & $0.84^{\mathrm{c}}$ & $0.52^{b}$ & $1.12^{\mathrm{a}}$ & $0.88^{\mathrm{d}}$ & $0.57^{b}$ & $0.99^{a}$ \\
\hline Drought & $0.93^{\mathrm{a}}$ & $0.74^{\mathrm{a}}$ & $1.40^{\mathrm{e}}$ & $1.27^{\mathrm{c}}$ & $1.11^{\mathrm{bc}}$ & $1.24^{\mathrm{ac}}$ \\
\hline Heat stress & $0.88^{\mathrm{a}}$ & $1.28^{b}$ & $1.50^{\mathrm{c}}$ & $1.65^{\mathrm{d}}$ & $1.71^{\mathrm{d}}$ & $1.84^{\mathrm{e}}$ \\
\hline \multicolumn{7}{|c|}{$\mathrm{PAO}(\mu \mathrm{mol} / \mathrm{min} / \mathrm{g} \mathrm{FW})$} \\
\hline Control & $1.55^{\mathrm{c}}$ & $0.92^{\mathrm{b}}$ & $1.22^{\mathrm{b}}$ & $1.25^{\mathrm{a}}$ & $0.84^{\mathrm{d}}$ & $0.64^{\mathrm{a}}$ \\
\hline Drought & $2.07^{\mathrm{ab}}$ & $2.10^{c}$ & $2.85^{\mathrm{a}}$ & $3.30^{\mathrm{d}}$ & $2.69^{b}$ & $2.98^{\mathrm{c}}$ \\
\hline Heat stress & $1.98^{\mathrm{d}}$ & $2.61^{b}$ & $2.79^{c}$ & $2.29^{c}$ & $3.49^{\mathrm{ab}}$ & $2.36^{\mathrm{a}}$ \\
\hline \multicolumn{7}{|c|}{$\mathrm{ADC}(\mu \mathrm{mol} / \mathrm{min} / \mathrm{g} \mathrm{FW})$} \\
\hline Control & $0.68^{b}$ & $2.15^{\mathrm{a}}$ & $2.34^{\mathrm{a}}$ & $2.30^{\mathrm{a}}$ & $1.96^{\mathrm{c}}$ & $0.97^{\mathrm{d}}$ \\
\hline Drought & $1.13^{\mathrm{a}}$ & $1.30^{\mathrm{b}}$ & $1.80^{\mathrm{a}}$ & $2.75^{\mathrm{c}}$ & $2.15^{\mathrm{d}}$ & $0.93^{\mathrm{b}}$ \\
\hline Heat stress & $1.35^{\mathrm{b}}$ & $1.08^{\mathrm{b}}$ & $1.77^{\mathrm{a}}$ & $1.89^{\mathrm{c}}$ & $2.01^{\mathrm{d}}$ & $1.70^{\mathrm{a}}$ \\
\hline \multicolumn{7}{|c|}{$\mathrm{ODC}(\mu \mathrm{mol} / \mathrm{min} / \mathrm{g} \mathrm{FW})$} \\
\hline Control & $1.43^{\mathrm{b}}$ & $2.24^{\mathrm{c}}$ & $1.76^{\mathrm{a}}$ & $0.94^{\mathrm{d}}$ & $2.14^{\mathrm{e}}$ & $1.63^{\mathrm{a}}$ \\
\hline Drought & $1.45^{\mathrm{a}}$ & $1.43^{\mathrm{a}}$ & $1.29^{c}$ & $1.53^{\mathrm{c}}$ & $2.15^{\mathrm{d}}$ & $2.00^{\mathrm{c}}$ \\
\hline Heat stress & $0.95^{\mathrm{a}}$ & $1.07^{\mathrm{a}}$ & $1.24^{b}$ & $0.47^{\mathrm{c}}$ & $1.36^{\mathrm{d}}$ & $1.40^{\mathrm{d}}$ \\
\hline
\end{tabular}

Different letters indicate significant differences $(p>0.05)$ between genotypes according to Tukey's test. CON - control, D - drought, HS - heat stress.

Polyamine content increased under both drought and heat stress condition but highest content was observed under drought (Table 2). Putrescine (Put), spermidine (Spd) and spermine $(\mathrm{Spm})$ content increased under both the stresses in all genotypes. However, PBW 621 showed reduction in Spd content under drought stress. Spermine (Spm) level was maximum in HD 2967 under drought and in PBW 621 under HT stress.

\section{Effect of heat and drought stress on TBARS, $\mathrm{H}_{2} \mathrm{O}_{2}$ and lignin content}

Heat and drought stress caused significant changes in cell wall lignification pattern. There was an increase in lignin content under both heat and drought stress conditions (Table 2) 
Table 2. Effect of drought and heat stress on TBARs, $\mathrm{H}_{2} \mathrm{O}_{2}$, lignin, putrescine, spermidine, spermine content in leaves of six wheat genotypes

\begin{tabular}{|c|c|c|c|c|c|c|}
\hline \multicolumn{7}{|c|}{ TBARS (nmol/g FW) } \\
\hline Genotypes & PBW 343 & PBW 550 & PBW 175 & PBW 621 & C 306 & HD 2967 \\
\hline Control & $3.89^{\mathrm{a}}$ & $4.10^{\mathrm{a}}$ & $10.79^{\mathrm{b}}$ & $7.78^{c}$ & $6.91^{\mathrm{bc}}$ & $9.07^{\mathrm{c}}$ \\
\hline Drought & $22.46^{\mathrm{c}}$ & $38.00^{\mathrm{ab}}$ & $33.00^{\mathrm{a}}$ & $25.38^{\mathrm{ab}}$ & $18.36^{\mathrm{d}}$ & $29.00^{\mathrm{b}}$ \\
\hline Heat stress & $17.60^{\mathrm{ab}}$ & $15.88^{\mathrm{c}}$ & $14.26^{\mathrm{ab}}$ & $16.09^{\mathrm{b}}$ & $10.80^{\mathrm{d}}$ & $16.74^{\mathrm{e}}$ \\
\hline \multicolumn{7}{|c|}{$\mathrm{H}_{2} \mathrm{O}_{2}(\mu \mathrm{mol} / \mathrm{g} \mathrm{FW})$} \\
\hline Control & $4.96^{\mathrm{c}}$ & $5.17^{\mathrm{bc}}$ & $9.89^{\mathrm{c}}$ & $7.48^{\mathrm{abc}}$ & $6.85^{\mathrm{a}}$ & $9.42^{\mathrm{ab}}$ \\
\hline Drought & $7.76^{\mathrm{a}}$ & $8.13^{\mathrm{c}}$ & $8.00^{\mathrm{a}}$ & $11.64^{\mathrm{b}}$ & $13.58^{\mathrm{a}}$ & $11.96^{\mathrm{b}}$ \\
\hline Heat stress & $11.16^{\mathrm{a}}$ & $10.26^{\mathrm{ab}}$ & $11.27^{\mathrm{d}}$ & $9.37^{\mathrm{bc}}$ & $12.13^{\mathrm{e}}$ & $8.89^{c}$ \\
\hline \multicolumn{7}{|c|}{ Lignin (mg/g FW) } \\
\hline Control & $121^{\mathrm{a}}$ & $130^{\mathrm{b}}$ & $155^{\mathrm{c}}$ & $132^{\mathrm{b}}$ & $156^{\mathrm{c}}$ & $162^{\mathrm{c}}$ \\
\hline Drought & $153^{\mathrm{a}}$ & $116^{\mathrm{b}}$ & $165^{\mathrm{a}}$ & $123^{\mathrm{b}}$ & $180^{\mathrm{c}}$ & $176^{\mathrm{c}}$ \\
\hline Heat stress & $139^{a}$ & $162^{\mathrm{b}}$ & $185^{\mathrm{c}}$ & $155^{\mathrm{a}}$ & $195^{\mathrm{c}}$ & $193^{\mathrm{c}}$ \\
\hline \multicolumn{7}{|c|}{ Put $(\mu \mathrm{mol} / \mathrm{g} \mathrm{FW})$} \\
\hline Control & $3.00^{\mathrm{a}}$ & $5.85^{\mathrm{b}}$ & $3.89^{\mathrm{ab}}$ & $6.06^{\mathrm{b}}$ & $6.95^{\mathrm{c}}$ & $9.57^{\mathrm{d}}$ \\
\hline Drought & $9.15^{\mathrm{ab}}$ & $9.99^{\mathrm{ab}}$ & $9.75^{\mathrm{a}}$ & $13.35^{\mathrm{ab}}$ & $13.7^{\mathrm{a}}$ & $11.15^{\mathrm{b}}$ \\
\hline Heat stress & $6.00^{\mathrm{c}}$ & $8.00^{\mathrm{a}}$ & $6.38^{\mathrm{a}}$ & $7.80^{\mathrm{b}}$ & $8.1^{\mathrm{b}}$ & $7.66^{\mathrm{a}}$ \\
\hline \multicolumn{7}{|c|}{ Spd $(\mu \mathrm{mol} / \mathrm{g} \mathrm{FW})$} \\
\hline Control & $2.05^{\mathrm{a}}$ & $3.52^{\mathrm{ab}}$ & $3.49^{\mathrm{ab}}$ & $4.66^{\mathrm{b}}$ & $7.99^{\mathrm{c}}$ & $4.02^{\mathrm{ab}}$ \\
\hline Drought & $7.99^{\mathrm{b}}$ & $7.42^{\mathrm{ab}}$ & $6.44^{\mathrm{ab}}$ & $3.48^{\mathrm{c}}$ & $8.23^{\mathrm{b}}$ & $8.37^{\mathrm{b}}$ \\
\hline Heat stress & $6.83^{\mathrm{c}}$ & $6.77^{\mathrm{ab}}$ & $5.94^{\mathrm{ab}}$ & $9.54^{\mathrm{b}}$ & $8.02^{\mathrm{ab}}$ & $5.57^{\mathrm{a}}$ \\
\hline \multicolumn{7}{|c|}{$\mathrm{Spm}(\mu \mathrm{mol} / \mathrm{g} \mathrm{FW})$} \\
\hline Control & $1.28^{\mathrm{a}}$ & $2.38^{\mathrm{ab}}$ & $2.37^{\mathrm{ab}}$ & $5.45^{\mathrm{c}}$ & $5.21^{\mathrm{c}}$ & $2.64^{\mathrm{ab}}$ \\
\hline Drought & $4.74^{\mathrm{ab}}$ & $5.97^{\mathrm{ab}}$ & $5.17^{\mathrm{ab}}$ & $3.58^{\mathrm{ab}}$ & $6.00^{\mathrm{ab}}$ & $7.37^{\mathrm{b}}$ \\
\hline Heat stress & $4.00^{\mathrm{a}}$ & $4.50^{\mathrm{b}}$ & $3.83^{\mathrm{a}}$ & $6.50^{\mathrm{c}}$ & $4.70^{\mathrm{a}}$ & $4.72^{\mathrm{a}}$ \\
\hline
\end{tabular}

Different letters indicate significant differences $(p>0.05)$ between genotypes according to Tukey's test. CON - control, $\mathrm{D}$ - drought, HS - heat stress

which corresponds to its intense staining patterns detected histochemically (Fig. 1). The effect of heat stress was more severe in cultivars PBW 343 and PBW 550 as shown by less colouration of leaf sections. Lignin content was maximum in PBW 175 and C 306 under drought stress whereas, HT enhanced lignin content in C 306, HD 2967, and PBW 175 (Table 2).

Thiobarbituric acid reactive substances (TBARS) content increased under heat and drought stress in all the cultivars. Drought caused severe damage to cell membrane as there was higher content of TBARs in all six genotypes (Table 2). Maximum TBARS content was observed in cultivars PBW 550 and PBW 343. Hydrogen peroxide content also increased under stress conditions in all genotypes (Table 2) but maximum accumulation was observed in PBW 621, PBW 175 (drought) and C 306 (heat stress). 
(a) CONTROL

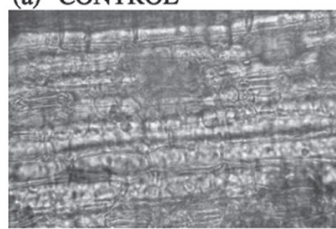

(d)

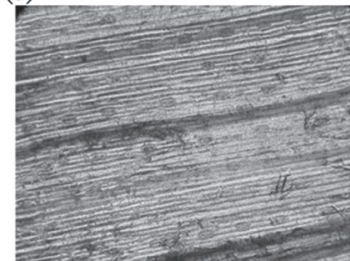

(a) DROUGHT

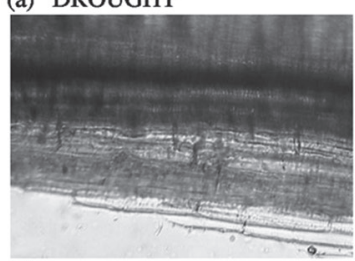

(d)

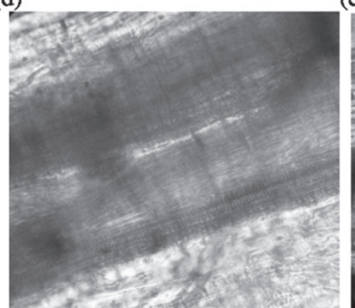

(a) HEAT STRESS

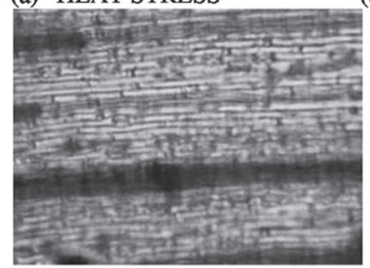

(d)

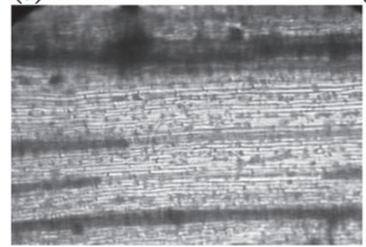

(b)

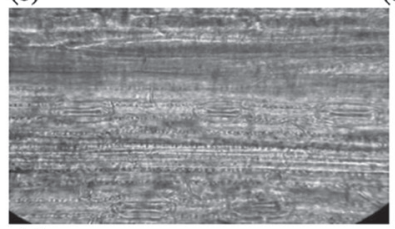

(e)

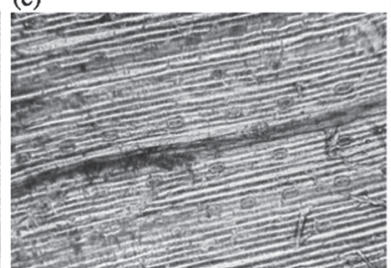

(b)

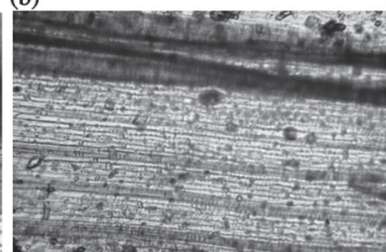

(e)

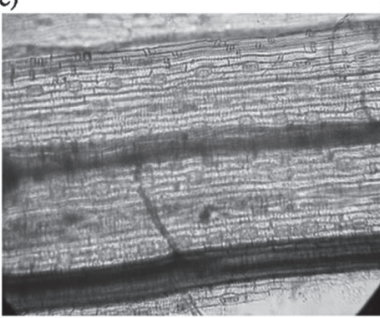

(b)

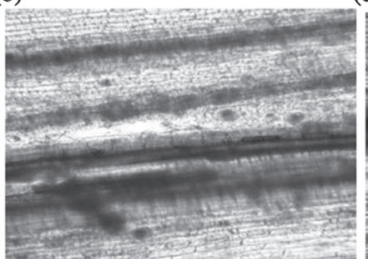

(e)

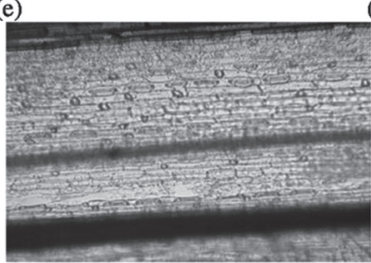

(c)

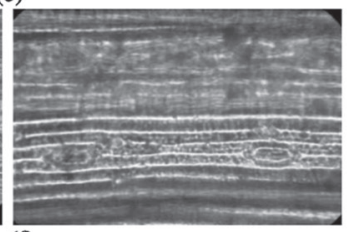

(f)

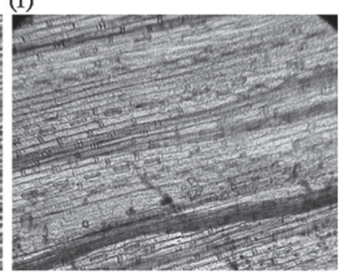

(c)

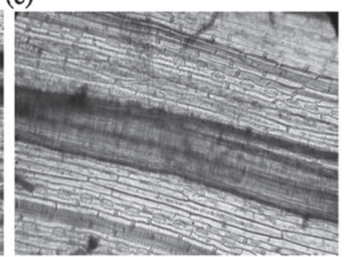

(f)

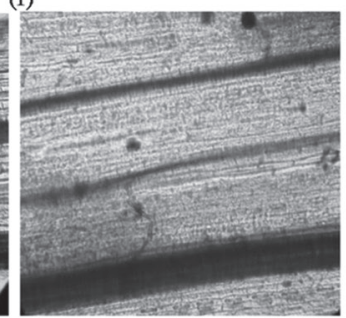

(c)

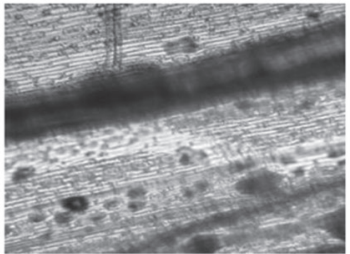

(f)

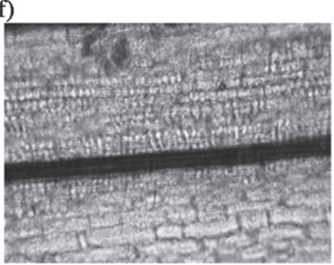

Figure 1. Histochemical localization of lignin in cell walls of leaves at vegetative stage (55 days after sowing) of six wheat genotypes (a) PBW 343, (b) PBW 550, (c) PBW 175, (d) PBW 621, (e) C 306, (f) HD 2967 under control, drought and heat stress conditions. Hand cut macerated sections of leaves were dipped in phloroglucinol (2\%) for $10 \mathrm{~min}$ and in conc. $\mathrm{HCl}$ for $2 \mathrm{~min}$ at room temperature. Sections were then photographed under an Olympus motorized system microscope (CX41, Olympus Co., Tokyo, Japan) at 400 magnification 


\section{Discussion}

It has been well established that polyamines (PAs) play important role in defence of plants against diverse environmental stress (Groppa and Benavides 2008). Our previous study indicated the role of amine oxidase in production of $\mathrm{H}_{2} \mathrm{O}_{2}$ leading to cell wall lignification in certain cells of wheat grain structure, however, their clear role in PAs metabolising enzymes was incomplete. Therefore, exact mechanism by which PAs enhances this tolerance mechanism in relation to wall associated peroxidases (POXs) that induce lignification need to be further explored.

Heat and drought stress lead to enhanced production of reactive oxygen species (ROS) that primarily triggers lipid peroxidation of cell membranes in form of thiobarbituric acid reactive substances (TBARs) content (Oktem et al. 2008). Higher injury to membranes under stress corresponds to excessive production of free radical especially TBARs and $\mathrm{H}_{2} \mathrm{O}_{2}$ content in PBW 343 and PBW 550 (Table 2). However, cultivars C 306, HD 2967, PBW 175 and PBW 621 maintained less membrane injury over cultivars PBW 343 and PBW 550 indicating their higher membrane stability. Similar to our observation, Hu et al. (2010) also observed marked production of $\mathrm{H}_{2} \mathrm{O}_{2}$ and TBARs content under heat and drought stress conditions. In agreement with previous studies, these results showed that higher activities of POXs are associated with lower ROS accumulation and hence less membrane injury under heat and drought stress, especially in stress tolerant genotypes (Gao et al. 2008).

Heat and drought stress not only changes membrane structure but also affects PAs synthesising enzymes. Interestingly, arginine decarboxylase (ADC) activity increased in cultivars C 306 and PBW 621 leading to enhanced production of PAs (Put, Spd and $\mathrm{Spm})$. It has been well documented that higher levels of PAs could confer plant tolerance to abiotic stress by acting as direct ROS scavengers or binding to antioxidant enzyme molecules to scavenge free radicals (Groppa and Benavides, 2008). Infact, ADC seems to be the key enzyme responsible for PAs biosynthesis in wheat leaves under both the stresses (Table 1) and our results are further supported from the observations of Bouchereau et al. (1999) in maize plant where ADC was the main pathway not ODC in PAs biosynthesis. It was inferred that PAs acted as an antioxidant machinery to counteract oxidative stress produced under heat and drought stress. However, out of the three main polyamines (Put, Spd and Spm), Put seems to play a central role in stress tolerance due to its higher content and thus scavenges ROS leading to reduced oxidative damage as also observed by Shu et al. (2015) under salt stress. It is generally believed that higher PAs can bind strongly to the negative charges in cellular components such as proteins and phospholipids and thereby stabilize the membranes under stress conditions (Asthir et al. 2004; Liu et al. 2007).

An increased activity of antioxidant enzymes especially POXs constitute the main cellular defence mechanism against oxidative stress as POX utilizes $\mathrm{H}_{2} \mathrm{O}_{2}$ for lignification and this increases cell wall rigidity under stress (Duan et al. 2008). Peroxidases showed higher activities in cultivars, i.e. C 306, PBW 175 and HD 2967 under both heat and drought stress. In a similar fashion, an increase in activities of GPX, CPX and SPX 
correlated well with increased content of lignin measured both spectrophotometrically (Table 2) and histochemically (Fig. 1). However, SPX was the major enzyme responsible for cell wall lignifications and tolerance of the cultivars under stress conditions. Earlier reports also indicated that $\mathrm{H}_{2} \mathrm{O}_{2}$ released during activity of POXs stimulated wall associated lignifications (Ros-Barcelo et al. 2002). The activities of the polyamine metabolising enzymes, are induced by stresses, resulting in enhanced stress tolerance. A number of studies have demonstrated that polyamines function in stress tolerance largely by modulating the homeostasis of reactive oxygen species (ROS) due to their direct, or indirect, roles in regulating antioxidant systems or suppressing ROS production (Liu et al. 2015).

Polyamine catabolism via DAO and PAO activities also increased in conjunction with an increase in $\mathrm{H}_{2} \mathrm{O}_{2}$ content under heat and drought stress. Both the catabolism and backconversion of polyamines by DAO and PAOs result in the production of $\mathrm{H}_{2} \mathrm{O}_{2}$ in the apoplast and peroxisomes (Magda et al. 2015). Previous studies suggest that higher content of $\mathrm{H}_{2} \mathrm{O}_{2}$ in tolerant cultivars reveals their role as a signalling molecule under abiotic stress (Denness et al. 2011). Maximum accumulation of $\mathrm{H}_{2} \mathrm{O}_{2}$ and lignin content in PBW 175, PBW 621 and C 306 further supported that higher lignification strengthens cell wall especially via PAO activity. Infact, both DAO and PAO are responsible in supplying $\mathrm{H}_{2} \mathrm{O}_{2}$ for cell wall lignification but in our study PAO seems to be the predominant enzyme over DAO due to its higher activity in leaves. Higher PAO activity in C 306, PBW 621 and PBW 175 under drought and HT demonstrated its superior tolerance mechanism in terms of higher $\mathrm{H}_{2} \mathrm{O}_{2}$ production and utilization. This was corroborated further with higher detection of lignin which correlates with increased activities of POX and PAO.

We believe that the increases in Put, Spd and Spm levels that occurred during the stress conditions in our experiments were primarily due to increase in their biosynthetic enzymes. As the activities of ADC and ODC increased, contents of polyamine also increased. The commonly known PAs, putrescine, spermidine, and spermine tend to accumulate together accompanied by an increase in the activities of their biosynthetic enzymes under a range of environmental stresses (Pathak et al. 2014).

In conclusion, our study indicates that both heat and drought tolerance is depicted by different mechanisms in wheat genotypes. Heat stress mainly led to PAs degradation via PAO activity, which serves as a main source of apoplastic $\mathrm{H}_{2} \mathrm{O}_{2}$ for SPX mediated lignification in cultivar C 306 and HD 2967. This high degree of lignification may be responsible for the tolerance of these cultivars by strengthening their cell wall under heat stress conditions. Whereas, drought stress tolerance was primarily associated with increased PAs contents by stimulating PA biosynthetic enzymes (ADC) in cultivars PBW 175 and PBW 621 to enhance their cell membrane stability.

\section{References}

Asthir, B., Duffus, C.M., Smith, R.C. Spoor, W. 2002. Diamine oxidase is involved in $\mathrm{H}_{2} \mathrm{O}_{2}$ production in the chalazal cells during barley grain filling. J. Exp. Bot. 53:677-682.

Asthir, B., Spoor, W., Duffus, C.M. 2004. Involvement of polyamine, diamine oxidase and polyamine oxidase in resistance of barley to Blumeria graminis f. Sp. hordei. Euphytica 136:307-312. 
Birecka, H., Bitonti, A.J., McCann, P.P. 1985. Assaying ornithine and arginine decarboxylase in some plant species. Plant Physiol. 79:509-514.

Bouchereau, A., Aziz, A., Larher, F., Martin-Tanguy, J. 1999. Polyamines and environmental challenges: recent development. Plant Sci. 140:103-125.

Denness, L., McKenna, J.F., Segonzac, C., Wormit, A., Madhou, P., Bennett, M., Mansfield, J., Zipfel, C., Hamann, T. 2011. Cell wall damage-induced lignin biosynthesis is regulated by a reactive oxygen species and jasmonic acid dependent process in Arabidopsis. Plant Physiol. 156:1364-1374.

Dhillon-Grewal, R., Virk, D.S., Mangat, B.K., Basra, R.K., Basra, A.S. 1992. Polyamine levels in anthers of poly-cytoplasmic isonuclear male sterile lines of pearl millet. Bot. Bull. Acad. Sin. 33:97-100.

Duan, J.J., Li, J., Guo, S., Kang, Y. 2008. Exogenous spermidine affects polyamine metabolism in salinitystressed Cucumis sativus roots and enhances short-term salinity. J. Plant Physiol. 165:1620-1635.

Gao, J.M., Xiao, Q., Ding, L.P., Chen, M.J., Yin, L., Li, J.Z., Zhou, S.Y., He, G.Y. 2008. Differential responses of lipid peroxidation and antioxidants in Alternanthera phioxeroides and Oryza sativa subjected to drought stress. Plant Growth Regul. 56:89-95.

Goyal, M., Asthir, B. 2010. Polyamine catabolism influences antioxidative defense mechanism in shoots and roots of five wheat genotypes under high temperature stress. Plant Growth Regul. 60:13-25.

Groppa, M.D., Benavides, M.P. 2008. Polyamines and abiotic stress: recent advance. Amino Acids 34:35-45.

Heath, R.L., Packer, L. 1968. Photoperoxidation in isolated chloroplasts. I. Kinetics and stoichiometry of fatty acid peroxidation. Arch. Biochem. Biophys. 125:189-198.

Hu, W.H., Xiao, Y.A., Zeng, J.J., Hu, X.H. 2010. Photosynthesis, respiration and antioxidant enzymes in pepper leaves under drought and heat stresses. Biol. Plant. 54:761-765.

Iannone, M.F., Rosales, E.P., Groppa, M.D., Benavides, M.P. 2013. $\mathrm{H}_{2} \mathrm{O}_{2}$ involvement in polyamine-induced cell death in tobacco leaf discs. J. Plant Growth Regul. 32:745-757.

Kotak, S., Larkindale, J., Lee, U., von Koskull-Doring, P., Vierling, E., Scharf, K.D. 2007. Complexity of heat stress response in plants. Curr. Opin. Plant Biol. 10:310-316.

Kumar, S., Kaur, R., Kaur, N., Bhandhari, K., Kaushal, N., Gupta, K., Bains, T.S., Nayyar, H. 2011. Heat-stress induced inhibition in growth and chlorosis in mungbean (Phaseolus aureus Roxb.) is partly mitigated by ascorbic acid application and is related to reduction in oxidative stress. Acta Physiol. Plant. 33:2091-2101.

Lee, T.M, Lin, Y.H. 1995. Changes in soluble and cell wall-bound peroxidase activities with growth in anoxiatreated rice (Oryza sativa L.) coleoptiles and roots. Plant Sci. 106:1-7.

Lin, C.C., Kao, C.H. 2001. Cell wall peroxidase activity, hydrogen peroxidase level and NaCl-inhibited root growth of rice seedling. Plant Soil. 230:135-143.

Liu, H.P., Dong, B.H., Zhang, Y., Liu, Z.P., Liu, Y.L. 2010. Relationship between osmotic stress and the levels of free, conjugated and bound polyamines in leaves of wheat seedlings. Plant Sci. 166:1261-1267.

Liu, J.H., Kitashiba, H., Wang, J., Ban, Y., Moriguchi, T. 2007. Polyamine and their ability to provide environmental stress tolerance to plants. Plant Biotechnol. 24:117-126.

Liu, J.H., Wang, W., Wu, H., Gong, X., Moriguchi, T. 2015. Polyamines function in stress tolerance: from synthesis to regulation Front. Plant Sci. 6:827.

Magda, P., Szalai, G., Janda, T. 2015. Speculation: Polyamines are important in abiotic stress signalling. A review. Plant Sci. 237:16-23.

Nakashima, J., Chen, F., Jackson, L., Shadle, G., Dixon, R.A. 2008. Multi-site genetic modification of monolignol biosynthesis in alfalfa (Medicago sativa): effects on lignin composition in specific cell types. New Phytol. 179:738-750.

Oktem, H.A., Eyidooan, F., Demirba, D., Bayrac, A.T., Oz, M.T., Ozgur, E., Selcuk, F., Yucel, M. 2008. Antioxidant responses of lentil to cold and drought stress. J. Plant Biochem. Biotechnol. 17:15-21.

Pathak, M.R., da Silva, J.A.T., Wani, S.H. 2014. Polyamines in response to abiotic stress tolerance through transgenic approaches. GM Crops and Food 5:87-96.

Quiroga, M., Guerrero, C., Botella, M.A., Barcelo, A., Amaya, I., Medina, M.I., Alonso, F.J., Forchetti, S.M., Tigier, H., Valpuesta, V. 2000. A tomato peroxidase involved in the synthesis of lignin and suberin. Plant Physiol. 122:1119-1127. 
Ros-Barcelo, A., Pomar, F., Lopes-Serrano, M., Martinez, P., Pendreno, M.A. 2002. Developmental regulation of the $\mathrm{H}_{2} \mathrm{O}_{2}$ producing system and basic peroxidase isoenzyme in the Zinnia elegans lignifying xylem. Plant Physiol. Biochem. 40:325-332.

Savidge, R., Udagama-Randeniya, P., 1992. Cell-wall-bound coniferyl alcohol oxidase associated with lignification in conifers. Phytochem. 31:2959-2966.

Sergiev, I., Alexieva, V., Karanov, E. 1997. Effect of spermine, atrazine and combination between them on some endogenous protective systems and stress markers in plants. C. R. Acad. Bulg. Sci. 51:121-124.

Shu, S., Yuan, Y., Chen, J., Jin, S., Zhang, W., Tang, Y., Zhong, M., Guo, S. 2015. The role of putrescine in the regulation of proteins and fatty acids of thylakoid membranes under salt stress. Scientific Reports DOI: $10.1038 /$ srep 14390

Suzuki, N., Mittler, R. 2006. Reactive oxygen species and temperature stresses: a delicate balance between signalling and destruction. Physiol. Plant. 126:45-51.

Tao, S., Khanizadeh, S., Zhang, H., Zhang, S. 2009. Anatomy, ultrastructure and lignin distribution of stone cells in two Pyrus species, Plant Sci. 176:413-419.

Zao, F.G., Liu, Y.L. 2000. Study on determination of ADC and TGase activities. Plant Physiol. Commun. 36:442-444. 